\title{
Laminar fate specification in the cerebral cortex
}

\section{Nicolas Gaspard and Pierre Vanderhaeghen*}

\author{
Address: Institute for Interdisciplinary Research (IRIBHM), Université Libre de Bruxelles (ULB), Campus Erasme, 808 Route de Lennik, \\ B-1070 Brussels, Belgium \\ *Corresponding author: Pierre Vanderhaeghen (pierre.vanderhaeghen@ulb.ac.be) \\ FI000 Biology Reports 20II, 3:6 (doi:10.3410/B3-6) \\ This is an open-access article distributed under the terms of the Creative Commons Attribution-Non Commercial License \\ (http://creativecommons.org/licenses/by-nc/3.0/legalcode), which permits unrestricted use, distribution, and reproduction in any medium, \\ provided the original work is properly cited. You may not use this work for commercial purposes. \\ The electronic version of this article is the complete one and can be found at: http://fl000.com/reports/b/3/6
}

\begin{abstract}
The cerebral cortex is composed of hundreds of different types of neurons, which underlie its ability to perform highly complex neural processes. How this astonishing cell diversity is generated during development constitutes a major challenge in developmental neurosciences, with important implications for neurological diseases. Here we review some recent and exciting advances in this field, from the description of the cellular processes at the origin of cortical neuron diversity, to the dissection of the molecular logic underlying fate selection in cortical neurons.
\end{abstract}

\section{Introduction}

The cerebral cortex is arguably the most complex structure in the mammalian brain, consisting of hundreds of distinct neuronal subtypes, each connected to a specific part of the brain. Neuronal diversity is at the core of cortical function and underlies its most sophisticated tasks that set us apart as higher mammals, such as language, reasoning, and memory. Understanding the mechanisms underlying this diversity may one day allow us to repair the damage wrought to the cerebral cortex by aging and trauma.

Neurons of the cerebral cortex belong to two broad classes: excitatory pyramidal neurons and inhibitory interneurons. Pyramidal neurons, named after their triangularshaped cell body, can be categorized further into dozens of subtypes, each characterized by specific morphology, electrophysiology, and connectivity [1]. Cortical neurons are not arranged randomly in space; the location of a pyramidal neuron in a specific cortical area and layer broadly predicts its participation in a modality-specific neuronal network. The surface of the cortex consists of areas of neurons that are specialized in particular functions, such as vision or language. In addition, each area is divided through its thickness into six different layers (laminae), which contain specific subtypes of neurons. The laminar position of a neuron is correlated with its pattern of connectivity (Figure 1). Corticofugal neurons are located in the deep layers of the cortex (layers 5 and 6) and mainly send their axons to subcortical structures (such as the basal ganglia, thalamus, brainstem, and spinal cord) whereas corticocortical-projecting neurons, which connect one region of the cortex to another, and especially callosal-projecting neurons, whose axons project into the corpus callosum, reside mostly in the upper layers 2 and 3. Layer 4 neurons on the other hand mainly receive input from the rest of brain.

The six-layer organization is central to cortical function and is highly conserved in all mammals despite the fact that the cortex has grown in complexity throughout recent mammalian evolution. This leads us to question the developmental mechanisms involved that link early embryonic events with later phases of patterning of connectivity. In addition, the identification of the factors that can (re)specify the identity of cortical neurons, and thereby their patterns of connectivity, could have major implications for future therapeutic strategies aimed at repairing the cortex following injury or degeneration.

Here, we will review recent and exciting advances in the understanding of the mechanisms that control the generation of pyramidal neuron diversity and their relation to laminar patterns of neuronal fate. 
Figure I. Laminar organization and pattern of cortical projections

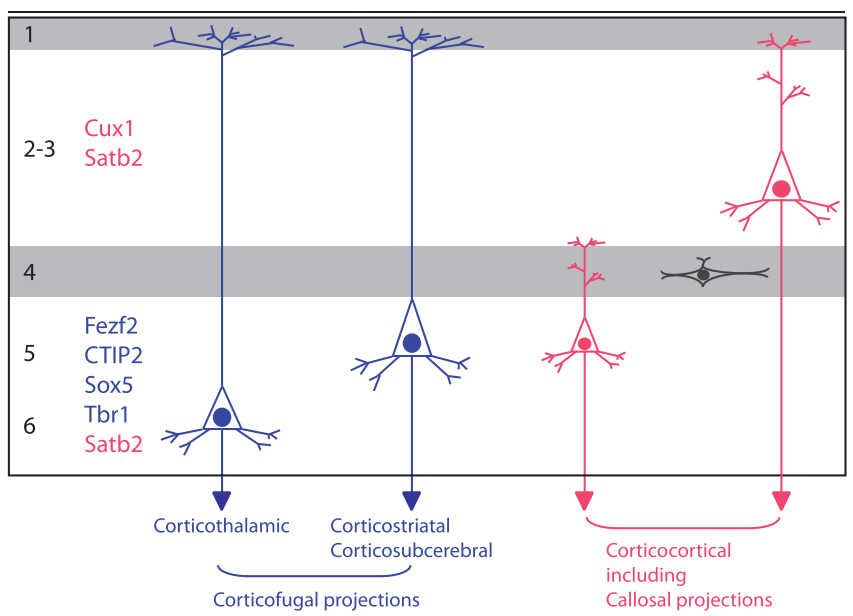

Simplified scheme depicting the laminar organization of the cortex in terms of gene expression and axonal projections. Neurons sending corticofugal projections (in blue) reside exclusively in the deep layers 5 and 6 of the cortex, while those sending projections within the cortex (in red), including callosal projections to the contralateral side, reside primarily in the upper layers, with a small contingent of callosal-projecting neurons in layer 5. Each subtype expresses specific combinations of transcription factors (in blue and red).

\section{Diversity starts in cortical progenitors}

The entire pyramidal neuronal population arises from cortical progenitor cells in the proliferative zones of the dorsal forebrain. These progenitors constitute a diverse population of cells with distinct molecular and cellular properties that scientific research has only just begun to unveil (Figure 2).

Among the cortical progenitors are the radial glial cells, which constitute a major subtype (reviewed in $[2,3]$ ). They are characterized by their unique morphology, consisting of a contact with the ventricular surface and a radial projection stretching from the ventricular zone (the most apical cell layer that lines the ventricle) to the outer, or basal, surface of the cortex. Radial glial cells undergo stereotypical patterns of symmetric and asymmetric cell divisions, thereby enabling the generation of diverse types of neurons while maintaining a pool of progenitors, thus following stem cell-like behavior [4,5].

In addition to radial glial cells, several other types of progenitors have been identified that are likely to contribute to neuronal diversity $[4,6,7]$. Of special interest among these are basal progenitors, which are also called intermediate progenitor cells $[4,8]$. Newly generated intermediate progenitor cells migrate to the upper part of the ventricular zone to create an additional proliferative zone above it, called the subventricular zone. Unlike radial glial cells, intermediate progenitor cells divide
Figure 2. Diversity of cortical progenitors

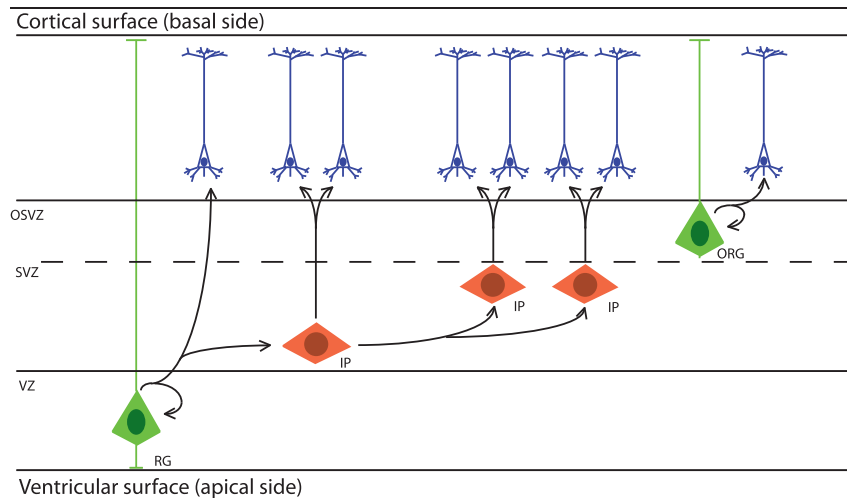

Several types of cortical progenitors and their modes of division towards neurons (in blue) are depicted, including radial glial cells (RG), intermediate progenitors (IP), and outer radial glial cells (ORG), with their specific location in ventricular (VZ), subventricular (SVZ) or outer subventricular (OSVZ) zones.

symmetrically only once or twice before generating neurons and thus act as transit amplifying cells. As there seems to be a correspondence in the expression of markers between subventricular-zone intermediate progenitor cells and upper-layer neurons $[9,10]$, it was proposed that upper-layer neurons arise mainly from intermediate progenitor cells. This was recently confirmed in mice through the analysis of the function of various genes, such as $T b r 2, A p 2 \gamma$, and Insm1, that were shown to be required for IP-cell specification and amplification, as well as upper-layer neuron specification [11-15]. Interestingly, some of these studies also revealed that intermediate progenitor cells are involved in the generation of some deep-layer neurons as well, so there is no unequivocal link between one type of progenitor and one type of cortical neuron.

The diversity of progenitors has also been proposed to contribute to the evolution and complexification of the cerebral cortex. As intermediate progenitor cells are progressively more abundant in higher mammals and primates, it was proposed that the observed increase in the relative number of upper-layer neurons in higher mammals may also be due to an expansion of the subventricular zone or altered properties of intermediate progenitor cells $[16,17]$. However, another major type of progenitor has now been described within a specialized compartment of the human developing cortex called the outer subventricular zone $[18,19]$. These so-called "outer" radial glial cells share many features with regular radial glial cells, including the potential for self-renewal, but they lack any apical projection (Figure 2). As these cells have only been found so far in human and ferret cortex, and not in any smaller-sized and/or simpler 
cortex, they might constitute a species-specific feature that could underlie the expansion or complexification of the cortex in higher mammals.

\section{Acquisition of laminar fate through temporal patterning}

In vivo lineage-tracing analyses have revealed that cortical progenitors generate radial clones that consist of neurons arranged in multiple layers. Interestingly, a prominent feature of this process is its time dependence; that is, cortical progenitors generate different layers of neurons at distinct developmental stages. As corticogenesis proceeds, newly generated neurons migrate radially past the ones generated earlier to progressively create the six cortical layers in which neurons are located, according to their birth date, in an inside-out fashion. Early-generated neurons thus reside in deep layers and late-generated neurons in the upper layers [20]. It remains unknown how cortical progenitors use time-dependent intrinsic and extrinsic cues to generate distinct types of neurons [21]. Somewhat surprisingly, in vitro studies using dissociated cortical progenitors [22] or even cortical progenitors derived from embryonic stem cells [23] have revealed that the temporal sequence of cell division and neuron specification is also conserved within clones of cortical cells arising from a single progenitor. This suggests that, at least in vitro, some progenitors are multipotent and are capable of generating multiple types of neurons in a lineage-intrinsic pattern by changing their competence (i.e., their capacity to respond to intrinsic and extrinsic differentiation cues) over time. The molecular mechanisms underlying this intriguing process remain largely unknown, although it is reminiscent of similar time-dependent clonal neurogenesis described in the fly embryo $[24,25]$.

\section{Towards a molecular logic of specification of cortical neurons}

While the data reviewed above have provided an important framework to understand the generation of neuronal diversity in the cortex, they do not explain how neuronal fate choices are instructed in the cortex, particularly in relation to layer identity and patterns of connectivity. This important issue has begun to be addressed recently through the discovery of genes that are expressed in neuron subtype-specific patterns at the time of their differentiation. Several of these genes were identified through a connectivity-based screening strategy, where different subtypes of cortical neurons were first isolated on the basis of their patterns of axonal projections, followed by the analysis of their transcriptome [26].

Among the genes identified in this screen, Fezf2 was found to be expressed in corticospinal projection neurons $[26,27]$. In Fezf2-mutant mice, deep-layer neurons are generated normally but fail to mature and to extend axons to their subcortical targets such as spinal cord [27-30]. Most strikingly, the development of corticofugal neurons is not only blocked in these mutants but is also partially switched to other fates (Figure 3), as they display many properties of callosal-projecting neurons, such as sending their axons to the contralateral cortex $[27,31]$. Conversely, overexpression of Fezf2 in late progenitors leads to the generation of neurons displaying corticofugal instead of callosal projections $[27,29,31]$. Although this fate switch is incomplete $[28,29,31]$, the data suggest that Fezf2 is one of the master genes for the specification of corticofugal neurons. This was strikingly illustrated by a recent study showing that Fezf2 overexpression in progenitors of the ventral forebrain, normally fated to generate striatal neurons, resulted in their respecification into corticofugal neurons [32].

Fezf2 was thus isolated as a gene that is selectively expressed among distinct neuronal subtypes, but it seems to act mainly within progenitors. While this confirms that patterns of cortical neuron diversity emerge in cortical progenitors, recent data indicate that this diversity also builds up within differentiating neurons themselves, through genes acting downstream of Fezf2 within different types of cortical neurons to instruct them to acquire specific patterns of identity and connectivity (Figure 3 ). One such gene is Ctip2, which is downregulated in Fezf2mutants $[27,28,31]$. It is one of the first genes found to be expressed specifically among corticofugal neurons [26]. Ctip2 is expressed by these neurons during development and in the postnatal period until adulthood, and is especially enriched in layer 5 corticospinal-projecting neurons [26]. In Ctip2-mutant mice, corticospinal axons do not reach their normal targets, a similar picture to that seen in Fezf2-mutants. Overexpression of Ctip2 is able to rescue the axonal projection phenotype in Fezf2-mutant mice and to instruct some upper-layer neurons to extend aberrant subcortical projections in normal mice, suggesting that it acts as a major effector of Fezf2 in the development of subcortical projections [31].

Another interesting gene identified in corticofugal neurons is Sox5 $[33,34]$. In Sox5-mutant mice, it is not only the final fate of corticofugal neurons that is altered but also the timing of their generation and laminar fate $[33,34]$. Corticothalamic and corticospinal neurons fail to segregate in their specific layers and the corticospinal tract, although present, is abnormal [34]. Interestingly, the additional loss of Ctip2 reverses some of the defects observed, suggesting that the normal role of Sox5 is to repress the early expression of Ctip2 to correctly specify early-generated cortical neurons. Gain-of-function experiments in upper-layer neurons suggest that, at least at 
Figure 3. From genes to neuronal fates

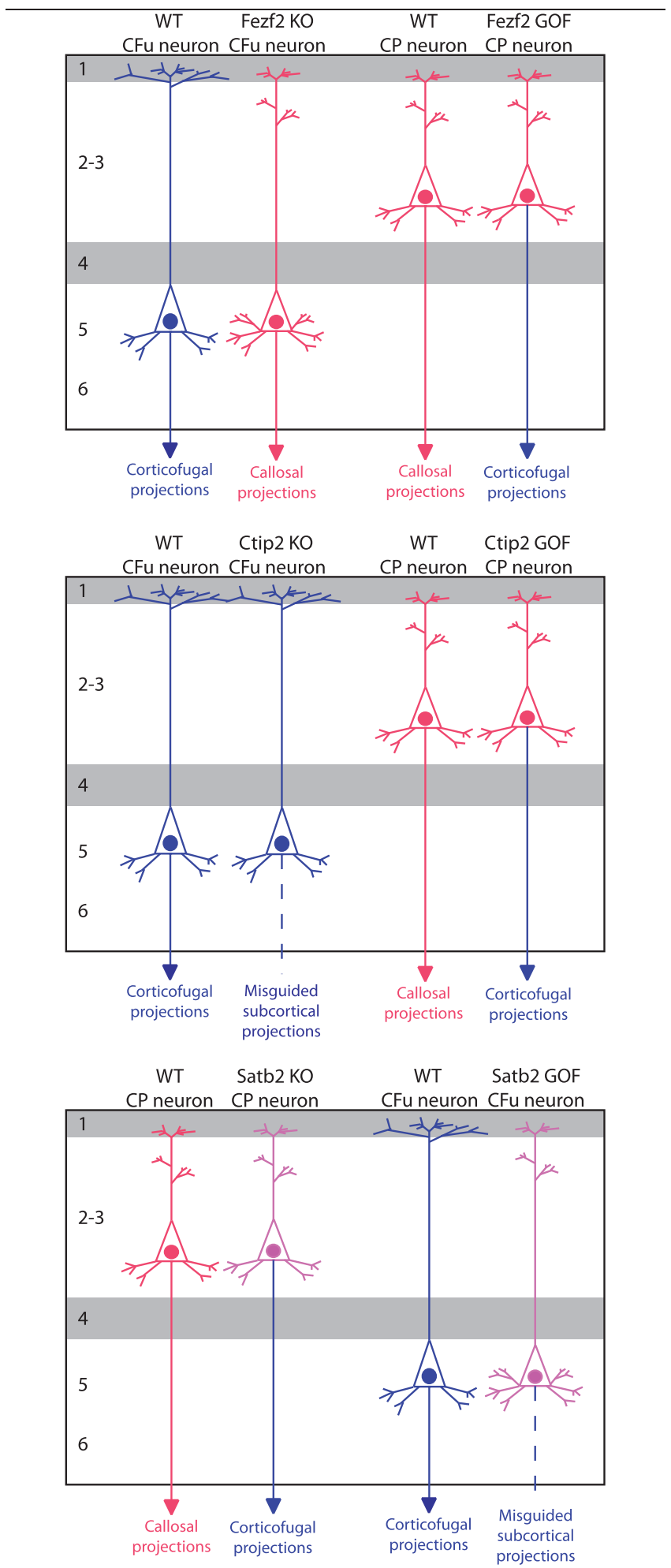

Scheme depicting the axonal projections of cortical neurons in normal (wild-type) conditions (WT) or following knockout (KO) or gain-of-function (GOF) of three major transcription factors involved in fate specification: Fezf2, Ctip2, and Satb2. See text for further explanation. certain time points, Sox5 is able to inhibit the growth of callosal-projecting neurons and promote corticofugal projections [33,34].

Besides the neuronal genes that "switch on" subcorticalprojecting neuron fate, others seem to promote the acquisition of upper-layer or callosal-projecting neuron fate. Among these, Satb2 is normally expressed in upperlayer neurons and in callosal-projecting neurons of layer 5 [35,36]. In Satb2-mutant mice, upper-layer neurons ectopically express Ctip2, but not Fezf2, and contribute to the corticospinal tract in place of the corpus callosum, which is absent $[35,36]$. Importantly, Satb2 was found to be able to repress Ctip2 expression, probably through direct chromatin modifications in the Ctip2 gene [35,36]. Conversely, while it is not clear whether Ctip 2 can actively repress Satb2, Fezf2 disruption results in ectopic expression of Satb2 among corticofugal-projection neurons [31]. Thus, Satb2, Ctip2, and Fezf2 take part in a genetic network enabling selection of neuronal fate, at least at the level of connectivity. In callosal-projecting neurons, Fezf2 is absent, so expression of Satb2 is possible, which in turn represses the expression of Ctip2 and leads to the development of callosal projections. In corticofugal neurons, Fezf2 is present and represses the expression of Satb2, while it induces the expression of Ctip2 and the development of corticofugal projections.

Overall, these data converge to suggest a model whereby the combinatorial expression of transcription factors leads to the precise specification of the different subtypes of deep-layer and corticofugal neurons on the one hand and callosal-projecting and upper-layer neurons on the other hand. This model remains fragmentary but constitutes a solid foundation to start unraveling the mechanisms of generation of cortical neuron diversity.

\section{Where to go next}

Recent advances have helped us to understand how the astonishing cellular diversity of the cerebral cortex arises, but many questions remain. Firstly, the extent of the diversity of the neural progenitors probably remains underestimated, and it will be crucial to determine the full range of this diversity, how it is established, and how it contributes to neuronal diversity. Another mystery to be solved is the molecular mechanism(s) that allows cortical progenitors to change competence in a time-dependent fashion, thereby generating even more diversity. Finally, how are the various features of the identity of a cortical neuron coordinated to achieve a proper match between laminar position and connectivity, and how is this related to the differentiation of cortical areas? Indeed, while recent work has also allowed us to gain insights into the mechanisms of areal specification, including the 
contribution of graded morphogens and transcription factors (reviewed in $[37,38]$ ), it is striking to note that a number of genes involved in this process may also control laminar fate [39-41]. This molecular link between areal and laminar patterning may provide the first hints as to how different areas are composed of the same six layers, but in distinct proportions.

Clearly, much more work will be needed to address all these complex questions. But together with the recent description of how diverse types of cortical neurons are generated from embryonic stem cells [42,43], a better knowledge of neuronal fate specification may provide unprecedented opportunities for the rational design of specific types of cortical neurons, which could be used to model specific types of cortical neuron diseases or pave the (still long) way towards cortical repair with replacement therapies.

\section{Competing interests}

The authors declare they have no competing interests.

\section{Acknowledgements}

The work of NG and PV was funded by grants from the Belgian FRS/FNRS, the Queen Elizabeth Medical Foundation, the Interuniversity Attraction Poles Programme, the Walloon Region Excellence Programme ("CIBLES"), and the WELBIO Programme. PV is a research director and NG was a doctoral fellow of the FNRS.

\section{References}

I. Molyneaux BJ, Arlotta P, Menezes JR, Macklis JD: Neuronal subtype specification in the cerebral cortex. Nat Rev Neurosci 2007, 8:427-37.

2. Pinto L, Gotz M: Radial glial cell heterogeneity-the source of diverse progeny in the CNS. Prog Neurobiol 2007, 83:2-23.

3. Kriegstein A, Alvarez-Buylla A: The glial nature of embryonic and adult neural stem cells. Annu Rev Neurosci 2009, 32:149-84.

4. Noctor SC, Martinez-Cerdeno V, Ivic L, Kriegstein AR: Cortical neurons arise in symmetric and asymmetric division zones and migrate through specific phases. Nat Neurosci 2004, 7:1 36-44.

FI000 Factor II

Evaluated by Gordon Fishell 23 Feb 2004, Jaime García-Añoveros 16 Apr 2004, Francois Guillemot 02 Jul 2004

5. Miyata T, Kawaguchi A, Saito K, Kawano M, Muto T, Ogawa M: Asymmetric production of surface-dividing and non-surfacedividing cortical progenitor cells. Development 2004, | 3 I:3 |33-45.

6. Stancik EK, Navarro-Quiroga I, Sellke R, Haydar TF: Heterogeneity in ventricular zone neural precursors contributes to neuronal fate diversity in the postnatal neocortex. J Neurosci 2010, 30:7028-36.

FI000 Factor 7

Evaluated by Sam Pleasure 24 May 2010, Orly Reiner 25 May 2010

7. Mizutani K, Yoon K, Dang L, Tokunaga A, Gaiano N: Differential Notch signalling distinguishes neural stem cells from intermediate progenitors. Nature 2007, 449:35I-5.

FI000 Factor 9

Evaluated by Matthew John Smalley 26 Sep 2007, Judith S Eisen 22 Oct 2007
8. Noctor SC, Martinez-Cerdeno V, Kriegstein AR: Distinct behaviors of neural stem and progenitor cells underlie cortical neurogenesis. J Comp Neurol 2008, 508:28-44.

9. Tarabykin V, Stoykova A, Usman N, Gruss P: Cortical upper layer neurons derive from the subventricular zone as indicated by Svet I gene expression. Development 200 I, I 28: 1983-93.

10. Nieto M, Monuki ES, Tang H, Imitola J, Haubst N, Khoury SJ, Cunningham J, Gotz M, Walsh CA: Expression of Cux-I and Cux-2 in the subventricular zone and upper layers II-IV of the cerebral cortex. J Comp Neurol 2004, 479:168-80.

FI000 Factor 6 Evaluated by Jeffrey Macklis 3I Jan 2005

II. Arnold SJ, Huang GJ, Cheung AF, Era T, Nishikawa S, Bikoff EK, Molnar Z, Robertson EJ, Groszer M: The T-box transcription factor Eomes/Tbr2 regulates neurogenesis in the cortical subventricular zone. Genes Dev 2008, 22:2479-84.

12. Pinto L, Drechsel D, Schmid MT, Ninkovic J, Irmler M, Brill MS, Restani L, Gianfranceschi L, Cerri C, Weber SN, Tarabykin V, Baer K, Guillemot F, Beckers J, Zecevic N, Dehay C, Caleo M, Schorle H, Götz M: AP2gamma regulates basal progenitor fate in a region- and layer-specific manner in the developing cortex. Nat Neurosci 2009, I 2:1229-37.

FI000 Factor 8

Evaluated by Jeffrey Macklis 21 Jun 2010

13. Farkas LM, Haffner C, Giger T, Khaitovich P, Nowick K, Birchmeier C, Paabo S, Huttner WB: Insulinoma-associated I has a panneurogenic role and promotes the generation and expansion of basal progenitors in the developing mouse neocortex. Neuron 2008, 60:40-55.

FI000 Factor 6

Evaluated by Orly Reiner 03 Sep 2009

14. Sessa A, Mao CA, Hadjantonakis AK, Klein WH, Broccoli V: Tbr2 directs conversion of radial glia into basal precursors and guides neuronal amplification by indirect neurogenesis in the developing neocortex. Neuron 2008, 60:56-69.

FI000 Factor 6

Evaluated by Jeffrey Macklis 30 Jan 2009

15. Kowalczyk T, Pontious A, Englund C, Daza RA, Bedogni F, Hodge R, Attardo A, Bell C, Huttner WB, Hevner RF: Intermediate neuronal progenitors (basal progenitors) produce pyramidal-projection neurons for all layers of cerebral cortex. Cereb Cortex 2009, 19:2439-50.

16. Kriegstein A, Noctor S, Martinez-Cerdeno V: Patterns of neural stem and progenitor cell division may underlie evolutionary cortical expansion. Nat Rev Neurosci 2006, 7:883-90.

17. Fish JL, Dehay C, Kennedy H, Huttner WB: Making bigger brainsthe evolution of neural-progenitor-cell division. J Cell Sci 2008, | 2 1:2783-93.

18. Hansen DV, Lui JH, Parker PR, Kriegstein AR: Neurogenic radial glia in the outer subventricular zone of human neocortex. Nature 2010, 464:554-56I.

19. Fietz SA, Kelava I, Vogt J, Wilsch-Bräuninger M, Stenzel D, Fish JL, Corbeil D, Riehn A, Distler W, Nitsch R, Huttner WB: OSVZ progenitors of human and ferret neocortex are epithelial-like and expand by integrin signaling. Nat Neurosci 20 10, 13:690-9.

FI000 Factor II

Evaluated by Cliff Ragsdale 03 Nov 2010, Magdalena Goetz 31 Jan 2011

20. Leone DP, Srinivasan K, Chen B, Alcamo E, McConnell SK: The determination of projection neuron identity in the developing cerebral cortex. Curr Opin Neurobiol 2008, 18:28-35.

21. Okano H, Temple S: Cell types to order: temporal specification of CNS stem cells. Curr Opin Neurobiol 2009, 19: | | 2-9.

22. Shen $Q$, Wang $Y$, Dimos JT, Fasano CA, Phoenix TN, Lemischka IR, Ivanova NB, Stifani S, Morrisey EE, Temple S: The timing of cortical 
neurogenesis is encoded within lineages of individual progenitor cells. Nat Neurosci 2006, 9:743-5I.

FI000 Factor 18

Evaluated by Susan K McConnell 15 May 2006, Judith S Eisen 30 May 2006, Monte Gates I4 Jul 2006, Arturo Alvarez-Buylla 19 Oct 2006

23. Gaspard N, Vanderhaeghen P: From stem cells to neural networks: recent advances and perspectives for neurodevelopmental disorders. Dev Med Child Neurol 20I I, 53:13-7.

24. Pearson BJ, Doe CQ: Specification of temporal identity in the developing nervous system. Annu Rev Cell Dev Biol 2004, 20:619-47.

25. Jacob J, Maurange C, Gould AP: Temporal control of neuronal diversity: common regulatory principles in insects and vertebrates? Development 2008, 135:3481-9.

26. Arlotta P, Molyneaux BJ, Chen J, Inoue J, Kominami R, Macklis JD: Neuronal subtype-specific genes that control corticospinal motor neuron development in vivo. Neuron 2005, 45:207-2I.

FI000 Factor 10

Evaluated by Kathleen Rockland 28 Jan 2005, Susan K McConnell 24 Mar 2005

27. Molyneaux BJ, Arlotta P, Hirata T, Hibi M, Macklis JD: Fezl is required for the birth and specification of corticospinal motor neurons. Neuron 2005, 47:817-3I.

FI000 Factor 6

Evaluated by Gordon Fishell I4 Oct 2005

28. Chen B, Schaevitz LR, McConnell SK: Fezl regulates the differentiation and axon targeting of layer 5 subcortical projection neurons in cerebral cortex. Proc Natl Acad Sci U S A 2005, I02:17184-9.

29. Chen JG, Rasin MR, Kwan KY, Sestan N: Zfp3/2 is required for subcortical axonal projections and dendritic morphology of deep-layer pyramidal neurons of the cerebral cortex. Proc Natl Acad Sci U S A 2005, 102:17792-7.

30. Hirata T, Suda Y, Nakao K, Narimatsu M, Hirano T, Hibi M: Zinc finger gene fez-like functions in the formation of subplate neurons and thalamocortical axons. Dev Dyn 2004, 230:546-56.

31. Chen B, Wang SS, Hattox AM, Rayburn H, Nelson SB, McConnell SK: The Fezf2-Ctip2 genetic pathway regulates the fate choice of subcortical projection neurons in the developing cerebral cortex. Proc Natl Acad Sci U S A 2008, I 05: I I 382-7.

32. Rouaux $C$, Arlotta P: Fezf2 directs the differentiation of corticofugal neurons from striatal progenitors in vivo. Nat Neurosci 2010, 13:1345-7.

FI000 Factor 7

Evaluated by Hisashi Umemori 05 Nov 2010, Pierre Vanderhaeghen 10 Nov 2010
33. Kwan KY, Lam MM, Krsnik Z, Kawasawa YI, Lefebvre V, Sestan N: SOX 5 postmitotically regulates migration, postmigratory differentiation, and projections of subplate and deeplayer neocortical neurons. Proc Natl Acad Sci U S A 2008, I05: I602|-6.

34. Lai T, Jabaudon D, Molyneaux BJ, Azim E, Arlotta P, Menezes JR, Macklis JD: SOX5 controls the sequential generation of distinct corticofugal neuron subtypes. Neuron 2008, 57: 232-47.

35. Alcamo EA, Chirivella L, Dautzenberg M, Dobreva G, Fariñas I, Grosschedl R, McConnell SK: Satb2 regulates callosal projection neuron identity in the developing cerebral cortex. Neuron 2008, 57:364-77.

36. Britanova $O$, de Juan Romero $C$, Cheung A, Kwan KY, Schwark M, Gyorgy A, Vogel T, Akopov S, Mitkovski M, Agoston D, Sestan N, Molnár Z, Tarabykin V: Satb2 is a postmitotic determinant for upper-layer neuron specification in the neocortex. Neuron 2008, 57:378-92

37. O'Leary DD, Sahara S: Genetic regulation of arealization of the neocortex. Curr Opin Neurobiol 2008, I8:90-100.

38. Vanderhaeghen P, Polleux F: Developmental mechanisms patterning thalamocortical projections: intrinsic, extrinsic and in between. Trends Neurosci 2004, 27:384-91.

39. Bedogni F, Hodge RD, Elsen GE, Nelson BR, Daza RA, Beyer RP, Bammler TK, Rubenstein JL, Hevner RF: TbrI regulates regional and laminar identity of postmitotic neurons in developing neocortex. Proc Natl Acad Sci U S A 2010, 107:13129-34.

40. Joshi PS, Molyneaux BJ, Feng L, Xie X, Macklis JD, Gan L: Bhlhb5 regulates the postmitotic acquisition of area identities in layers II-V of the developing neocortex. Neuron 2008, 60:258-72.

4I. Tomassy GS, De Leonibus E, Jabaudon D, Lodato S, Alfano C, Mele A, Macklis JD, Studer M: Area-specific temporal control of corticospinal motor neuron differentiation by COUP-TFI. Proc Natl Acad Sci U S A 2010, 107:3576-8I.

42. Gaspard N, Bouschet T, Hourez R, Dimidschstein J, Naeije G, van den Ameele J, Espuny-Camacho I, Herpoel A, Passante L, Schiffmann SN, Gaillard A, Vanderhaeghen P: An intrinsic mechanism of corticogenesis from embryonic stem cells. Nature 2008, 455: $351-7$.

FI000 Factor 8

Evaluated by Yi Eve Sun 24 Sep 2008

43. Eiraku M, Watanabe K, Matsuo-Takasaki M, Kawada M, Yonemura S, Matsumura M, Wataya T, Nishiyama A, Muguruma K, Sasai Y: Selforganized formation of polarized cortical tissues from ESCs and its active manipulation by extrinsic signals. Cell Stem Cell 2008, 3:519-32. 